\title{
HOW TO CHANGE THE PAST IN ONE-DIMENSIONAL TIME
}

BY

\author{
ROBERTO LOSS
}

$\underline{\text { Penultimate draft }}$

Forthcoming in the Pacific Philosophical Quarterly

\begin{abstract}
The possibility of changing the past by means of time-travel appears to depend on the possibility of distinguishing the past as it is 'before' and 'after' the timetravel. So far, all the metaphysical models that have been proposed to account for the possibility of past-changing time-travels operate this distinction by conceiving of time as multi-dimensional, and thus by significantly inflating our metaphysics of time. The aim of this article is to argue that there is an intuitive sense in which past-changing time-travels are metaphysically possible also in one-dimensional time.
\end{abstract}

\section{Time-travel, changing the past, and multi-dimensional models}

On December $31^{\text {st }}$ 2010, Tim is in his time-machine, determined to travel back in time to 1920. At the very last instant of December $31^{\text {st }}$, right before the end of the countdown to the New Year, he presses the start button. One instant later, he finds himself in 1920...

According to Lewis (1976), there is a fairly intuitive sense in which Tim's time-travel story is not an impossibility, but just an oddity. In order to account for the possibility of timetravel he assumes an eternalist and four-dimensionalist ontology of time, according to which the world is a four-dimensional manifold of events, and a perdurantist of persistence theory (or worm theory), according to which change amounts to a qualitative difference between 
temporal parts. Within Lewis's theory, a time traveller, like anyone else, is a streak through the manifold of space-time. However he 'is not a streak like other streaks':

If he travels toward the past he is a zig-zag streak, doubling back on himself. If he travels toward the future, he is a stretched-out streak. And if he travels either way instantaneously, so that there are no intermediate stages between the stage that departs and the stage that arrives and his journey has zero duration, then he is a broken streak. (Lewis, 1976: 146)

According to the worm theory advocated by Lewis (1976), a non time-travelling person is a continuous four-dimensional worm, extended in time as well as in space, whose temporal parts stick together in virtue of a certain kind of 'mental, or mostly mental, continuity and connectedness'. Therefore, the only difference between a 'common person' and a person time-travelling to the past to a time before his birth is that, unlike common persons, the first segment of the temporal worm in which the time-traveller consists occurs actually later then its second segment (assuming that after the trip to the past the time traveller dies before his birth). However, the latest temporal parts of his later segment display, with respect to the earliest parts of his earlier segment, the same kind of continuity and regularity displayed by temporally adjacent temporal parts of a common person. This is what allows us to consider the two separate segments as parts of a unique, if broken, temporal worm, and therefore, of a unique person. Therefore, with respect to what Lewis calls the external time, the timetraveller's departure occurs after his arrival. However, from the point of view of the timetraveller himself (that is, with respect to what Lewis calls his personal time), his departure occurs before his arrival.

If you take the stages of a common person, they manifest certain regularities with respect to external time. Properties change continuously as you go along, for the most part, and in familiar ways. First come infantile stages. Last come senile ones. Memories accumulate. Food digests. Hair grows. Wristwatch hands move. If you take the stages of a time traveler instead, they do not manifest the common regularities with respect to 
external time. But there is one way to assign coordinates to the time traveler's stages $[\ldots]$ so that the regularities that hold with respect to this assignment match those that commonly hold with respect to external time. With respect to the correct assignment properties change continuously as you go along, for the most part, and in familiar ways. First come infantile stages. Last come senile ones. Memories accumulate. Food digests. Hair grows. Wristwatch hands move. The assignment of coordinates that yields this match is the time traveler's personal time. (Lewis, 1975, p. 148, my italics)

The moral of Lewis's account of time-travel could be roughly summarised by saying that there is no inconsistency in Tim's time-travelling to the past, provided that he has already been there, so to speak. The history of a world in which Tim time-travels to 1920 would first feature Tim's arrival in 1920, then his life in the 20's (and, say, his tragic death in 1927), then his birth in 1977, his graduation in physics in 2000, the defence of his Ph.D. dissertation in 2003, his obtainment of government funds for the 'Time-Machine Project' in 2005 (despite some initial misgivings) ${ }^{1}$, and finally, the moment in which he presses the start button of the time-machine on December $31^{\text {st }} 2010$. Understood in this way, it is only from the internal perspective of Tim's personal time that he appears in 1920 'one instant later' than having pressed the button in 2010. In fact, with respect to the external time, he actually appears in 192070 years before he activates his time-machine.

Suppose, however, that Tim had never been to 1920 'before'. Could he time-travel to 1920, and thereby change the past (at least as to his existence in the 20's)? The very idea of changing the past by travelling back in time might strike as a sheer logical impossibility: how could Tim both have existed and not have existed in 1920? Some philosophers, however, disagree. Friends of what van Inwagen (2010) has called (in honour of David Lewis) 'non-Ludovician time-travel' claim that changing the past by means of a time-travel is indeed metaphysically possible, provided that we inflate our metaphysics of time with an additional dimension $d$, in order to distinguish the way the past is, so to speak, 'before' and 'after' the past-changing time-travel. In the case of Tim's time-travel, this extra dimension 
allows us to distinguish the way 1920 is with respect to different coordinates on $d$, and to consistently say that Tim both exists in 1920 (with respect to the $d$-coordinate $d_{\mathrm{x}}$ ) and does not exist in 1920 (with respect to the $d$-coordinate $d_{\mathrm{y}}$ ).

According to Meiland (1974), time must be thought of not as a line, as it is commonly done, but as a two-dimensional plane, which can be presented as follows. On a diagonal line running from left to right and from the bottom up lie present moments. At the left of each moment $t$ on the diagonal there is a horizontal line, running from left to right up to $t$, representing the way the past is when $t$ is present. According to this model, while Tim does not exist in the 1920 located on the diagonal line (that is: the way 1920 is when it is present), Tim exists in the 1920 located on the horizontal line lying on the left of the 2011 of the diagonal line (that is: the way 1920 is when 2011 is present). ${ }^{2}$

According to Goddu (2003) and van Inwagen (2010), the possibility of changing the past requires the position of a higher-order temporal dimension ('hyper-time') so that, for instance, Tim can exist in 1920 with respect to a certain hyper-time $T_{x}$, and not exist in 1920 with respect to a hyper-earlier hyper-time $\mathrm{T}_{\mathrm{y}}{ }^{3}$

Finally, according to the branching model, what is required for Tim to Marty McFly his way around time is a branching tree of concrete possible worlds. The 1920 that is earlier than the 2010 in which Tim enters the time-machine is Tim-free. However, the Tim-free 1920 is one year later than a 1919, which is, in turn, one year earlier than an alternative 1920 in which Tim appears out of thin air in his time-machine. ${ }^{4}$

The position of an additional dimension to reality might appear to many a cumbersome ontological posit casting some relevant shadows on the very idea of pastchanging time-travel. However, wannabe past-changing time-travellers should not be discouraged. As a matter of fact, as I will argue in what follows, there is a fairly intuitive sense in which the past can be changed even in a (temporally) one-dimensional eternalist world. Therefore, if I am right, past-changing time-travel is not only metaphysically 
possible, but it is a far less extravagant and far-fetched metaphysically oddity than multidimensionalists had us believe.

\section{Changing the past in one-dimensional time}

Within his theory, Lewis endorses a perdurantist theory of persistence, according to which continuants are temporally extended worms having different temporal parts. However, his account appears to be perfectly compatible with an exdurantist theory of persistence (or stage theory), according to which continuants are (the) instantaneous stages (that perdurantists consider to be temporal parts of a continuant), which persists and change in time by having earlier or later temporal counterparts. ${ }^{5}$ For reasons that will be clear below, I will assume exdurantism as the correct theory of persistence.

Consider now the following platitude: The world changes. Things are different from how they used to be, and surely they will be different from how they currently are. In some sense, to say that the world changes seems to be just a way of saying that things change in time. However, exdurantism allows us to take this platitude at face value, and to consider the world itself as a continuant that changes in time. Let, in fact, for every time $t$, the ' $t$-temporal slice' (or ' $t$-slice') be the mereological sum of all the entities $x$, such that $x$ exists at $t$, and only at $t$. Each $t$-slice can be seen as a 'world-counterpart', and the earlier-later relation linearly ordering the $t$-slices can be taken to be the genidentity relation for the world (that is, the relation making all the $t$-slices 'stick together' as counterparts of a certain world; see Sider, 2001, p. 194). Therefore, a truth like 'the world was different' can be accounted for by the fact that the current temporal slice $s(t)$ has an earlier temporal counterpart $s\left(t^{\prime}\right)$ that is qualitatively different from $s(t)$.

Consider then the following possible world $\mathrm{W} 1$. W1 is qualitatively identical to the actual world up to 1989's last instant. Then, in the following ten years, nothing exists but a 
bunch of spheres (not existing before and) bouncing off each other in an otherwise empty space. Then, from the first instant of 2000 , things are qualitatively identical to the way things are in the actual world from 1990's first instant onwards. In other words, in W1 the events occurring from 1990 on are temporally shifted ten years in the future, and the ten-year gap is filled with a bunch of spheres that did not exist before, and do not exist from 2000 onwards.

Most people existing in 1989's last moment in W1 have temporal counterparts located in 2000. Such counterparts are located ten-years later in what Lewis calls the external time. However, from the point of view of their personal time, 1989's events occurred in the previous year. In W1, things are exactly the same in 2000 as in the actual 1990: calendars read '1990', people look one-year older than in 1989, and they speak of, say, the fall of Berlin's Wall as something that happened the year before. There appears thus to be an intuitive sense in which, in $\mathrm{W} 1$, the year 2000 in external time can be said to be the year '1990'. Not only is there a massive coordination between the perspectives of people's personal time, but the world itself in 2000 exhibits a certain kind of relevant similarity with the temporal slices occurring in 1989.

As a matter of fact, the notion of regularity that is central to the Lewisian definition of personal time, can be in principle extended from persons to worlds. Clearly, the actual world displays a kind of regularity in its persistence over time that is violated in W1. In W1 the passage from 1989 to 1990 is, for instance, highly irregular: in 1990 everything is annihilated and a bunch of spheres appear somewhere in the universe out of thin air. There is, however, a maximal proper part of $\mathrm{W} 1$ that exhibits the same kind of regularities found in the actual world, that is, the mereological sum of W1's initial segment up to 1989 and W1's final segment from 2000 onwards. Let us call this maximal proper part of W1, 'W2'. Each temporal slice belonging to the W2-block can thus be seen as a temporal counterpart of a world, which much like Tim in Lewis's time-travel scenario, is a broken streak, having a temporal counterpart in 1989 that has a future counterpart in 2000 but no counterpart during 
the 90's. The regularities displayed by W2 allow us to speak of W2's 'internal' time, so that it makes perfect sense to say that while the year 2000 is the year 2000 with respect to the external time, and occurs eleven years later than the 1989 external time, it is also the year 1990 in W2's internal time, occurring one year later than 1989 in W2's internal time (in what follows I will use 'e.t.' and 'i.t.' for external time and internal time).

Worlds like W1 are extravagant possibilities. However, if W1 were the actual world, it would still make sense to say that, for instance, Germany became re-united one year after the fall of Berlin's Wall. Even if we somehow came to know that the actual world is W1, we would still keep saying, in most cases, that a person born in 1977 is currently 35 years old, that World War II ended 67 years ago, et cetera. We might call 'external world' the mereological sum of every $t$-slice $t$ (like W1), and 'Lewis-regular world' any maximal part of an external world (if possibly 'broken' from the point of view of external time) exhibiting the same kind of regularities we suppose to hold in the actual world.

At this point, in order to make room for one-dimensional past-changing time-travel, all we need to add to our theory is the notion of 'quasi-regular' world, that is, a world that is 'Lewis-regular' possibly except for the sudden appearance and/or disappearance of an individual (a time-traveller) along its history. Consider, for instance, the following possible (external) world V1. On December 31st $2010 \mathrm{Tim}$ is in his time machine, determined to travel back to 1920, a time in which he did not exist. Right before the end of New Year's countdown he presses the start button of his time machine. One instant later, in 2011's (e.t.) first instant, everything is qualitatively identical to how things were in 1920's first instant, except for the presence of Tim and his time-machine. V1 is not a quasi-regular world. There are, however, two maximal parts of V1 that qualify as such. On the one hand we have the part of V1 that goes from, say, the Big Bang up to 2010's last instant (let this be 'V2'). On the other hand, we have the mereological sum of V1's past up to 1919's last instant and 2011 (Let this be 'V3'). Up to 1919 there is no difference between external time and the internal 
time of both V2 and V3. So, for instance, 1919 e.t. is identical to the internal 1919 of both V2 and V3. However, whereas 1920 e.t. is the internal 1920 of V2, the internal 1920 of V3 is the external 2011. There are thus two internal 1920s: the internal 1920 of V2 (occurring in 1920 e.t., which we can call ' $1920 a^{\prime}$ ') and the internal 1920 of V3 (occurring in 2011 e.t.'1920b'). In this sense, after Tim's time-travel (notice: literally after, in external time) the past - the 'internal past' - has changed: before Tim's time travel the internal 1920 was 1920a; after Tim's time-travel, the internal 1920 is $1920 \mathrm{~b}$.

There appears thus to be a fairly intuitive sense in which V1 is a world in which Tim time-travels to the past thereby changing it. The $t$-temporal slice in which the external 1919 consists in has two '1920' counterparts: the external 1920 (which is the internal 1920 of the world V2) and the external 2011 (which is the internal 1920 of the world V3). By moving from the external and V2-internal 2010 one-instant to the future, Tim's time-travel 'changes' the (internal) year 1920 from a Tim-free 1920 to a 1920 in which Tim appears out of thin air in his time-machine (See figure 1).

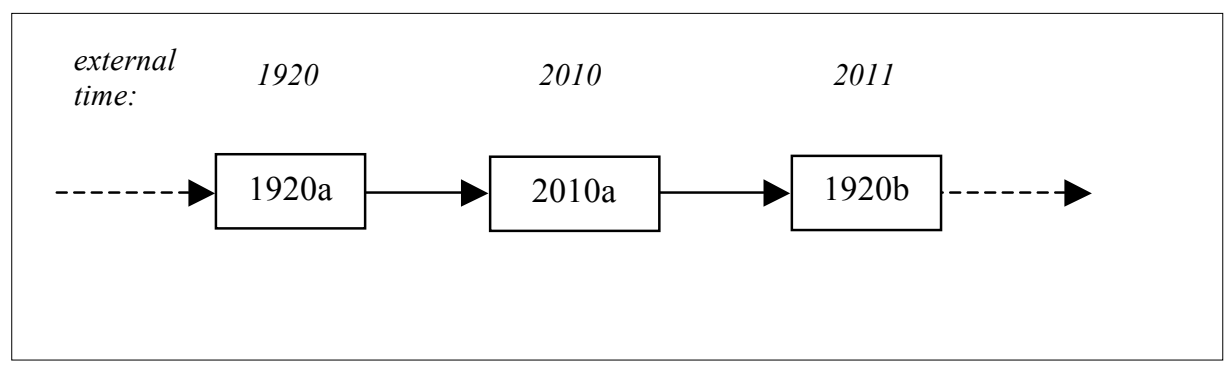

Figure 1. Tim's past-changing and one-dimensional time travel

Notice that the distinction between internal and external time is not an ontological one. The ontology I am employing here is exactly the same as the one featuring in a standard eternalist, four-dimensionalist, and B-theoretic setting. I am not positing the existence of either additional entities or additional temporal/modal dimensions to reality. The internal/external world/time distinction is semantic, boiling down to the claim that 'time', 
'past', 'year', '1920', and so on might be used either with respect to that unrestricted mereological fusion we usually call 'possible world', which I am here calling 'external world', or with respect to those restricted mereological fusions in which quasi-regular worlds consists and that can be called 'internal worlds', which are governed by a genidentity relation of similarity determined by the kind of regularities we suppose to hold in the actual world (possibly except for the sudden appearance and disappearance of a time-traveller).

\section{Internal worlds, fission and exdurantism}

As stated above, I am assuming in this paper an exdurantist theory of persistence, and I am considering worlds as being continuants. In this sense, a world is a stage (a $t$-temporal slice), which changes in virtue of having earlier or later qualitatively different counterparts. This means that in a world in which, like V1, an episode of past-changing time-travel occurs, what we have is a peculiar case of fission.

Consider the following scenario.

At time $t_{1}$ John enters a malfunctioning teleporter. At time $t_{2}$, while ' $a$ ' John is still in the teleporter, 'another' John appears where John wanted to be teleported.

According to the exdurantist account of fission, at $t_{1}$ there is one continuant, John, which has two future counterparts at $t_{2}$ : the John that is still in the teleporter, and the John standing right where John at $t_{1}$ intended to be teleported. In this way, the exdurantist can say that before the fission there is, for instance, only one person, while after the fission there are two. This appears to be a significant advantage of stage theory over the rival worm theory, which is seemingly forced to say that there are two coinciding persons even before the fission occurs. ${ }^{6}$ In John's scenario, the entities that result from the fission are simultaneous with each other. 
However, simultaneity does not appear to be a necessary condition in order to have a genuine case of fission. Consider for instance the following scenario.

In 2030, 20 year old Ted is in London, and is entering a teleporter, determined to go to Paris without wasting precious time. However, unbeknownst to him, the machine he is entering can function both as a teleporter and a time-machine. As it happens, when Ted presses the start-button the machine malfunctions, and he gets both teleported to Paris and sent 10 years into the future. One instant later, ' $a$ ' 20 year (plus one instant) old Ted appears in Paris and begins strolling along the Avenue des Champs-Élysées. He immediately falls in love with Paris, and decides to live there for the rest of his life. Unfortunately, 10 years later, in 2040, he gets killed in a car accident. Right when he breathes his last breath, a 'second' 20 year old Ted (plus one instant) appears inside the teleporter/time-machine in London ...

There appear to be no principled reasons not to consider Ted's as a case of fission, even if not of an ordinary kind. The Teds popping out of thin air in Paris in 2030 and in London in 2040 appear in fact to be related to the 'first' Ted in the same relevant way the two Johns appearing at $t_{2}$ are related to the 'first' John. However, Paris-2030-Ted and London-2040Ted are not simultaneous with each other. Ted's is, therefore, a case of what we might call asynchronic fission.

As in Ted's scenario, also in Tim's time travel scenario we have a case of asynchronic fission. The only difference is that, in Tim's case, what undergoes asynchronic fission is the world itself. At 1919 e.t. there exists one world stage which has two future ' 1920 ' counterparts: one existing at 1920 e.t.; the other existing at 2011 e.t.. This means that in Tim's scenario we have a peculiar case of branching, where what is branching is not the external world, but the internal one which, by undergoing fission, gives place to a peculiar 
'linear tree' of internal worlds (see figure 2). Therefore, this account of past-changing timetravel retains, in some sense, an essential feature of the branching model. The relevant difference is, however, that in this case the plurality of worlds that is required to change the past is 'folded', so to say, into a linear (external) world, thus not requiring any ontological inflation of standard eternalism.

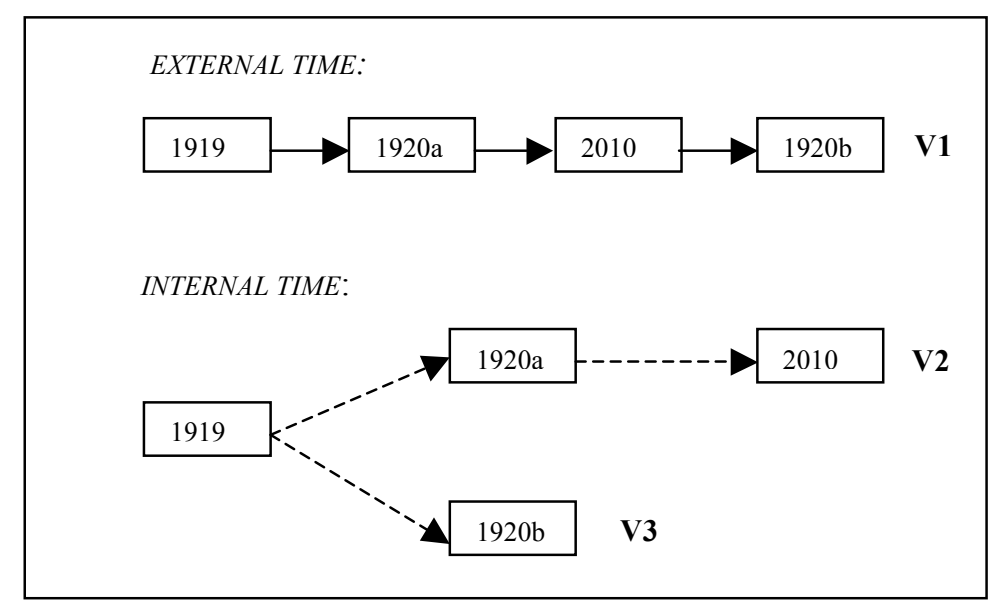

Figure 2. Linear external time and branching internal time

Once it is understood that, according to the theory that I am presenting, changing the past involves a case of fission, the reason why I prefer in this paper exdurantism over perdurantism as a theory of persistence should become clear. As a matter of fact, from what has been said so far, this theory of time-travel is perfectly compatible also with perdurantism, that is the theory according to which continuants are temporally extended temporal worms. However, assuming a perdurantist theory of fission, in Tim's scenario there are two different worlds all along, perfectly overlapping up to 1919 and diverging onwards (even if in an asynchronous way). Therefore, the 1920 in which Tim arrives is not really one year later than the 1919 that is one year earlier than the Tim-free 1920. According to perdurantism, in fact, as there are two internal 1920s, there are also two internal 1919s lying in two different worlds overlapping up to 1919: one 1919 is earlier than a Tim-free 1920, 
whereas the other is earlier than a 'Tim-ful' 1920. Therefore, as there are two worlds all along, Tim's looks more like a trans-world than an intra-world time-travel to the past. As a matter of fact, while it appears to be impossible that the past in which a past-changing timetraveller arrives is (in the strictest possible sense) the very same past that he left by entering the time-machine (the very same moment in time cannot, on pain of contradiction, be different from itself), it strikes as a necessary condition, in order for the arrival time of a time-travel to be truly considered as being 'the past', that it be at least later then the very same past (in the strictest possible sense) that, before the time travel took place, was earlier than 'the past' that the time-travel changes. In our case, for instance, in order for the 'new' 1920 in which Tim arrives (that is: 1920b) to be considered as 'the past', it appears necessary that it be later than the very same 1919 that was earlier than the 1920 that Tim changes by means of his time-travel (that is: 1920a). This is, therefore, why exdurantism should be preferred over perdurantism within this theory of time-travel. As a matter of fact, consistently with the exdurantist account of fission, although there are two internal $1920 \mathrm{~s}$ there is only one internal 1919, so that the 1920 in which Tim arrives (in 2011 e.t.: 1920b) is truly one year (internally) later than the same 1919 that is (internally and externally) earlier then the Tim-free 1920 (1920a).

\section{Times and change}

As we saw above, a $t$-slice (that is the mereological fusion of all the entities $x$, such that $x$ exists at time $t$, and only at $t$ ) can be considered both as an external world, and as an internal world. In the first case, the genidentity relation making a $t$-slice $x$ a counterpart of a certain $t$ slice $y$ is just the earlier-later relation. In the second case, it is a similarity relation tracking the kind of regularities we suppose to hold in the actual world, with the possible exception of the sudden appearance and disappearance of a time-traveler. However, a $t$-slice can also be 
seen as a time persisting and changing in time by having earlier and later counterparts. Consider, for instance, in Tim's scenario, the $t$-slice occurring in 1920 e.t.. 2011 e.t. is qualitatively identical to 1920 e.t. with the only exception of Tim's existence. However, this kind of 'almost-identity' is clearly ill-suited to count for as a counterpart relation for times. As a matter of fact, Tim might cause the world to be radically different in the new 1930 . However, we would still want the 'new' 1930 to be a future counterpart of the 'old' one. Therefore, at a first but relevant approximation, we could say that a time $x$ is a counterpart of a time $y$ if, and only if, there is a time $z$ such that both $x$ and $y$ are, for some $n, n$ internaltime-units later than $z$-where the notion of internal-time-units is to be analyzed in terms of the notion of internal time which, in turn, is to be analyzed in terms of the notion of quasiregular worlds.

(Internal) times themselves can thus be seen as persisting and changing in (external) time. Within an exdurantist account of persistence, to say that the year 1920 has changed is to say that the year 1920 is a continuant which has a qualitatively different past counterpart. This kind of change is precisely what is the case in Tim's universe according to the theory I am presenting. The internal 1920 changes from being Tim-free, to being Tim-ful. It persists and changes in (external) time by having qualitatively different temporal counterparts: one occurring in 1920 e.t., the other occurring in 2011 e.t.

Letting ' $a$ ' be the $t$-slice occurring in 1920 e.t., we can thus claim the following:

- qua external world, every other $t$-slice is a counterpart of $a$;

- qua internal world, all the $t$-slices occurring up to 2010 e.t. are counterparts of $a$, but the $t$-slice occurring at 2011 e.t. is not;

- qua time, $a$ has only one counterpart, that is 2011 e.t.. 


\section{Conclusion}

It appears unquestionable that a model for past-changing time-travel must distinguish the past as it is 'before' the time-travel from the past as it is 'after' the time-travel has taken place. This, in turn, entails that the same past must, in some sense, appear twice in the model: once as it was before the time-travel, and once as it has become after it has taken place. This thought has led many authors to conclude that some kind of ontological inflation is necessary to past-changing time-travel, and consequently, a proliferation of temporal(/modal) dimensions. As I have argued in this article, however, this conclusion is mistaken. According to exdurantism, for an entity $x$ to change is for it to have qualitatively different temporal counterparts. Once change is accounted for in this way, there is a fairly intuitive sense in which times, such as the year 1920, can have qualitatively different temporal counterparts, and thus change as an effect of a time-travel. If these lines of reasoning are correct, not only the model for past-changing time-travel presented in this article should be preferred over multi-dimensional ones as more parsimonious, but past-changing time-travels appear to be far less extravagant metaphysical oddities than multi-dimensionalists had us believe.?

Instituto de Investigaciones Filosóficas, Universidad Nacional Autónoma de México

\section{NOTES}

\footnotetext{
${ }^{1}$ See Casati \& Varzi (2001).

${ }^{2}$ On Meiland's planar model, the reader might find useful the animated diagrams at $A$ Time Travel Website (http://timetravelphilosophy.net/topics/multidimensional/).

${ }^{3}$ The question as to what are the differences between Goddu's and van Inwagen's model need not concern us here. What is important, for the issue at hand, is that (i) both postulates the existence of an
} 
additional dimension to reality, and that (ii) they both conceive of this extra dimension as a higherorder temporal order.

${ }^{4}$ See, for instance, Abbruzzese (2001).

${ }^{5}$ See, in particular, Sider (2001) and Hawley (2001).

${ }^{6}$ See Sider (2001, section 5.8) and Hawley (2001, section 5.7).

${ }^{7}$ I am grateful to an anonymous referee for The Pacific Philosophical Quarterly for useful comments. Many thanks to the Programa de Becas Posdoctorales en la UNAM, Instituto de Investigaciones Filosóficas, Universidad Nacional Autónoma de México (UNAM), for academic and financial support.

\section{REFERENCES}

Abbruzzese, J. (2001). 'On using the multiverse to avoid the paradoxes of time travel', Analysis 61 (1), pp. 36-38.

Carrol, J. W. ed. (2008). 'Multi-dimensional time'. A Time Travel Website. $<$ http://timetravelphilosophy.net/topics/multidimensional/>.

Casati, R. \& Varzi, A. C. (2001). 'That useless time machine', Philosophy 76 (4), pp. 581-583.

Goddu, G. C. (2003). 'Time travel and changing the past: (Or how to kill yourself and live to tell the tale)', Ratio 16 (1), pp.16-32.

Hawley, K. (2001). How things persist. Oxford University Press.

van Inwagen, P. (2010). 'Changing the Past', In Oxford Studies in Metaphysics, vol. 5, ed. Dean Zimmerman. Oxford: Oxford University Press, pp. 3-28.

Lewis, D. (1976). 'The Paradoxes of Time Travel', American Philosophical Quarterly 13 (2), pp. 145 152.

Meiland, J. W. (1974). 'A two-dimensional passage model of time for time travel'. Philosophical Studies 26 (3-4), pp. 153-173.

Sider, T. (2001). Four-dimensionalism. Oxford University Press. 